EXTENDED REPORT

\title{
Dendritic cells from patients with rheumatoid arthritis lack the interleukin 13 mediated increase of Fc $\gamma$ RII expression, which has clear functional consequences
}

\author{
T R D J Radstake, K C A M Nabbe, M H Wenink, M F Roelofs, A Oosterlaar, \\ A W T van Lieshout, P Barrera, P L E M van Lent, W B van den Berg
}

Ann Rheum Dis 2005;64:1737-1743. doi: 10.1136/ard.2004.034405

See end of article for authors' affiliations

Correspondence to: DrT R D J Radstake, Geert Grooteplein 8, $6500 \mathrm{HB}$ Nijmegen, The Netherlands; T.Radstake@ reuma.umen.nl

Accepted 23 April 2005 Published Online First 5 May 2005

\begin{abstract}
Background: Dendritic cell (DC) function is largely tailored by $\mathrm{Fc}$ gamma receptors (Fc $\gamma \mathrm{R})$ and is critical for every immune response.

Objective: To compare interleukin (IL) 13 mediated regulation of FcrRll and its related DC function between healthy controls and patients with rheumatoid arthritis (RA).

Methods: DC were derived from peripheral blood mononuclear cells according to standardised protocols. $\mathrm{F} c \gamma \mathrm{RI}$, II, and III expression and DC phenotype were assessed by FACS analysis. The level of cytokine production and chemokine expression was measured by Luminex and real time quantitative polymerase chain reaction techniques. Antigen uptake capacity was studied by DC fluorescent heat aggregated immunoglobulins and FACS analysis.

Results: Replacement of IL4 by IL13 clearly increased the expression of Fc $\gamma$ RII on DC from healthy controls (CDC), but had no effect on DC from patients with RA (RADC). The lower production of inflammatory mediators by IL13 CDC upon FcyR mediated triggering suggests that IL13 induces up regulation of specifically FcyRll. RADC co-cultured with IL4 already displayed an inhibitory DC phenotype, but this inhibitory phenotype was not augmented by the addition of IL13. The defective FcyRll regulation was further substantiated by the finding that IL13 CDC increased antigen uptake capacity, whereas ILI 3 RADC did not.

Conclusion: IL13 regulates the expression of inhibitory FcyRll in normal subjects but not in RA, potentially resulting in a chronic proinflammatory immune reaction in RA. Unravelling the underlying mechanisms of FcyRll regulation might lead to new therapeutic targets in RA.
\end{abstract}

$\mathrm{R}$ heumatoid arthritis (RA) is a chronic systemic autoimmune disease characterised by inflammation and destruction of the synovial joints. Although the precise mechanisms involved in its pathogenesis remain to be elucidated, it is clear that a massive influx of inflammatory cells, including macrophages and dendritic cells (DC), in the joint is one of its key elements. ${ }^{1}$ DC are the professional antigen presenting cells that control the innate and adaptive immune response, and orchestrate the balance between tolerance and immunity. ${ }^{2}$ Nowadays, evidence points towards the potential role for DC in both the initiation and perpetuation of synovial inflammation in RA. At first, DC are strategically located in the perivascular regions and ectopic lymphoid structures in RA synovium..$^{3-5}$ Secondly, in RA synovium DC-specific chemokines, including CCL17, CCL18, and CCL19, are significantly more highly expressed than in normal subjects. ${ }^{6}$ Finally, it has been shown that genetically modified DC can abrogate collagen induced arthritis, ${ }^{7}$ whereas collagen pulsed DC drive inflammatory arthritis. ${ }^{8}$

For the recognition and processing of antigens, DC are equipped with several receptors, including Fc gamma receptors $(\mathrm{F} c \gamma \mathrm{R})$. Fc $\gamma \mathrm{R}$ constitute a group of receptors designed to recognise IgG containing immune complexes (IC), which are abundantly present in serum and synovial fluid of patients with RA. ${ }^{9}$ In humans three classes can be distinguished, Fc $\gamma$ RI, Fc $\gamma$ RII, and Fc $\gamma$ RIII. ${ }^{10}{ }^{11}$ Fc $\gamma$ RII is further divided in two subtypes: Fc $\gamma$ RIIa and Fc $\gamma$ RIIb. Fc $\gamma$ RIIa, together with Fc $\gamma$ RI and III, activates cellular responses upon triggering. In contrast, Fc $\gamma$ RIIb is a unique inhibitory Fc $\gamma$ R. $^{12-14}$
Although the mechanism is not fully elucidated, it is generally accepted that the balance between activating and inhibitory Fc $\gamma \mathrm{R}$ is intimately controlled by pro- and antiinflammatory cytokines such as interleukin (IL) 4 and interferon $\gamma$ (IFN $\gamma)$. Pricop et al demonstrated that IL4 was responsible for the increased expression of inhibitory Fc $\gamma R$, whereas IFN $\gamma$ reversed this balance in favour of the activating Fc $\gamma \mathrm{R}$ subtypes. ${ }^{15}$ Interestingly, we have shown that monocyte derived DC from patients with RA with active disease expressed higher levels of the inhibitory Fc $\gamma$ RII than healthy donors, which was translated into an altered DC behaviour. ${ }^{5616}$ Perhaps, this increased expression of Fc $\gamma$ RIIb is explained by the presence of local factors during early DC development. IL4 is a plausible candidate, but is not found to be increased in RA. On the contrary, IL13, a cytokine which resembles many functions of IL4, is abundantly expressed in RA synovial fluid and highly secreted by synovial fluid macrophages during synovitis. ${ }^{17-19}$ The potential role for IL13 in regulating the balance of Fc $\gamma \mathrm{R}$ during RA is therefore more likely.

Accumulating evidence that points toward the critical situation for $\mathrm{Fc} \gamma \mathrm{R}$ in arthritis originates from experimental

Abbreviations: CDC, DC from healthy controls; DC, dendritic cell(s); FACS, fluorescence activated cell sorter; Fc $\gamma R$, Fc gamma receptor; HAGGs, heat aggregated gammaglobulins; IC, immune complex(es); iDC, immature monocyte derived DC; IFN $\gamma$, interferon $\gamma$; IL, interleukin; LPS, lipopolysaccharide; $\mathrm{mDC}$, fully matured DC; MFI, mean fluorescence intensity; MHC, major histocompatibility complex; PCR, polymerase chain reaction; RA, rheumatoid arthritis; RADC, DC from patients with RA; TNF $\alpha$, tumour necrosis factor $\alpha$ 
Table 1 Phenotypic characteristies of $\mathrm{DCC}$ and $\mathrm{mDC}$ from healthy donors and patients with RA

\begin{tabular}{|c|c|c|c|c|c|c|c|c|}
\hline \multirow[b]{2}{*}{ CD Marker } & \multicolumn{2}{|c|}{ Immature DC controls } & \multicolumn{2}{|c|}{ Immature DC RA } & \multicolumn{2}{|c|}{ Mature DC controls } & \multicolumn{2}{|c|}{ Mature DC RA } \\
\hline & $\%$ Cells & MFI & $\%$ Cells & MFI & $\%$ Cells & MFI & $\%$ Cells & MFI \\
\hline CDI4 & $10(7)$ & $26(11)$ & $13(9)$ & $28(10)$ & $6(4)$ & $22(7)$ & $8(5)$ & $18(11)$ \\
\hline CD80 & $51(24)$ & $26(13)$ & 50 (17) & $33(15)$ & $99(9)$ & $110(13)$ & 98 (7) & 99 (19) \\
\hline CD83 & $11(8)$ & $20(11)$ & $12(8)$ & $17(10)$ & 97 (8) & $53(16)$ & $91(8)$ & 61 (11) \\
\hline CD86 & 76 (15) & $105(25)$ & 69 (12) & $116(21)$ & $98(6)$ & $260(21)$ & $99(11)$ & $272(23)$ \\
\hline MHC-I & 90 (14) & $133(11)$ & $91(8)$ & $141(16)$ & $99(9)$ & $435(41)$ & $98(4)$ & 429 (34) \\
\hline MHC-II DP/DR & $92(11)$ & $264(18)$ & 85 (13) & $278(21)$ & $99(9)$ & $888(32)$ & $99(5)$ & $845(41)$ \\
\hline
\end{tabular}

arthritis models. In antigen induced arthritis and IC arthritis, for example, chondrocyte death and cartilage erosion are heavily dependent on the presence of activating $\mathrm{Fc} \gamma \mathrm{R} .^{20-22}$ Likewise, absence of the inhibitory Fc $\gamma$ RIIb renders mice susceptible to collagen induced arthritis, and it has been suggested that Fc $\gamma$ RIIb reduces both joint inflammation and destruction by inhibiting the activation of Fc $\gamma \mathrm{R}$ and clearance of IC..$^{14}{ }^{23}$ The finding that DC obtained from patients with RA express higher levels of the inhibitory FcyRIIb led us to speculate that inhibitory Fc $\gamma$ RII is up regulated during inflammation as a potent counteracting mechanism mediated by IC aimed at dampening the proinflammatory response. Here we postulate that IL13 has a critical role in the up regulation of FcrRIIb in healthy controls but that this response is absent in patients with RA, leading to an inadequate inhibition of the proinflammatory response which is normally mediated by IC.
Here we demonstrate that the up regulation of Fc $\gamma$ RII upon stimulation with IL13 in healthy donors is absent in RA, which results in an altered production of proinflammatory mediators. These findings provide evidence that the regulation of FC $\gamma R$ expression and related DC function might contribute to dampening of the immune response during normal conditions but fails in RA.

\section{PATIENTS AND METHODS}

\section{Patients}

Fifteen patients with RA and 16 healthy controls were enrolled in the present study. All patients fulfilled the American College of Rheumatology criteria for $\mathrm{RA}^{24}$ and gave informed consent for the study. Patients who received treatment with systemic steroids or biological agents (antitumour necrosis factor $\alpha$ (TNF $\alpha)$ and ILl receptor antagonist) were excluded from the study. The medical ethics committee
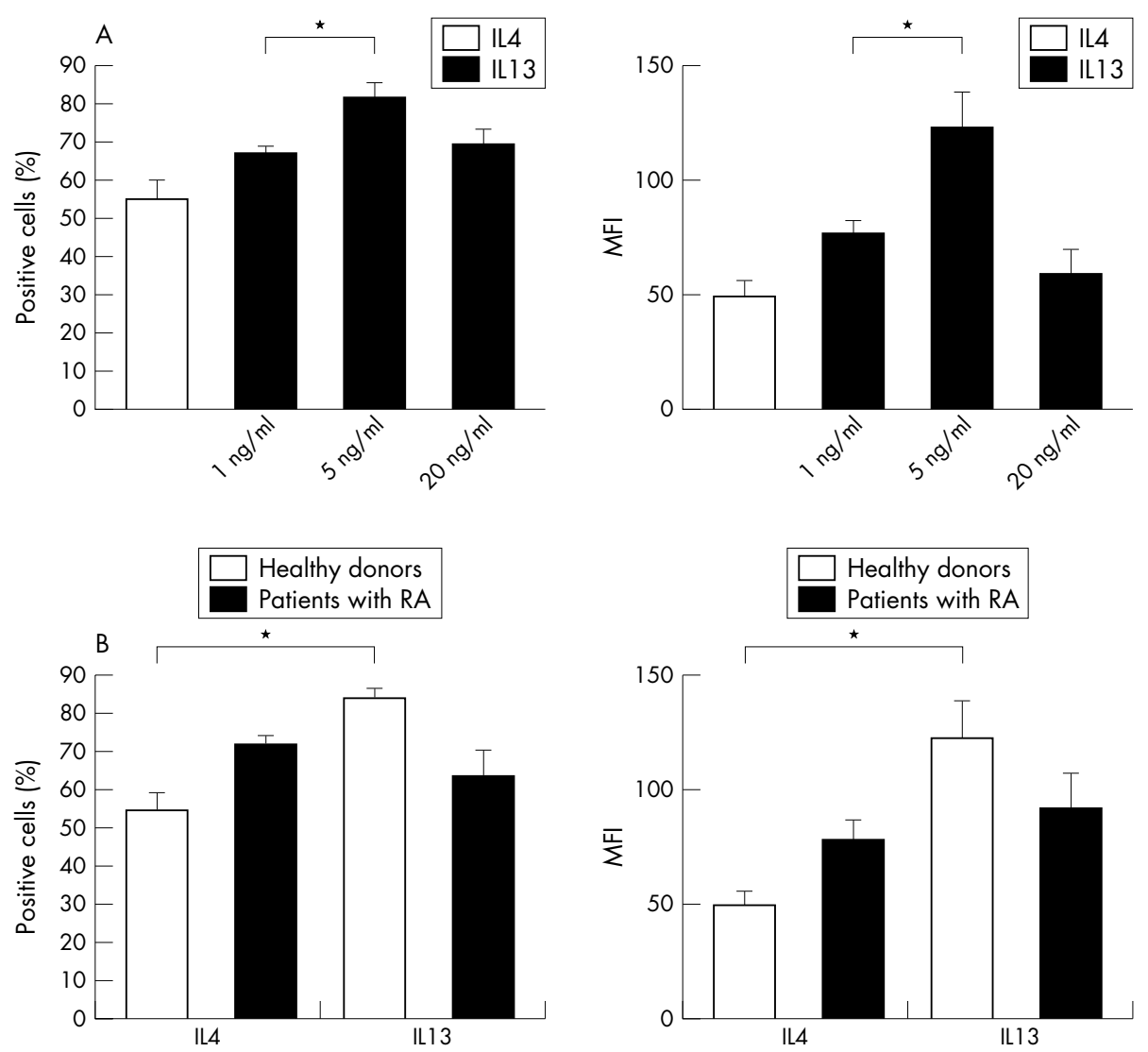

Figure 1 Expression of FcyRll upon replacement of IL4 by IL13 on DC of healthy controls and patients with RA. (A) Percentage of FcyRll positive cells (left panel) and MFI of FcyRll expression (right panel) after co-culture of DC from healthy donors $(n=16)$ with various concentrations of ILI3 and compared with IL4 $(500 \mathrm{U} / \mathrm{ml}$. (B) Comparison of the percentage of FcyRll positive cells (left panel) and mean fluorescence intensity (MFI) of Fc $\gamma \mathrm{RII}$ expression between DC from healthy donors $(\mathrm{n}=16)$ and patients with RA $(\mathrm{n}=15)$ co-cultured with IL4 $(500 \mathrm{U} / \mathrm{ml})$ and IL13 (5 ng/ml). ${ }^{*} \mathrm{p}<0.05$. 


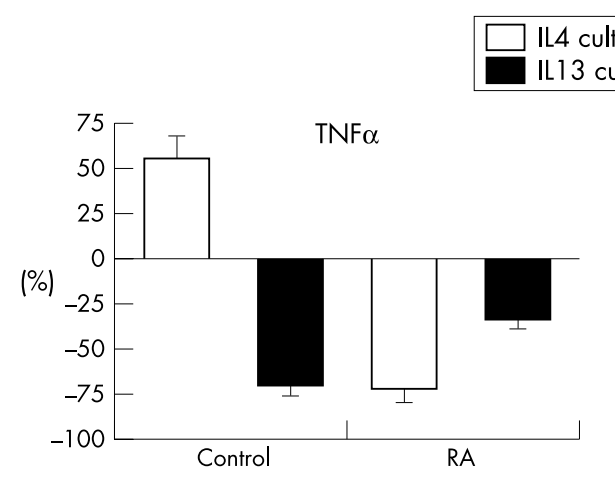

$(\%)$
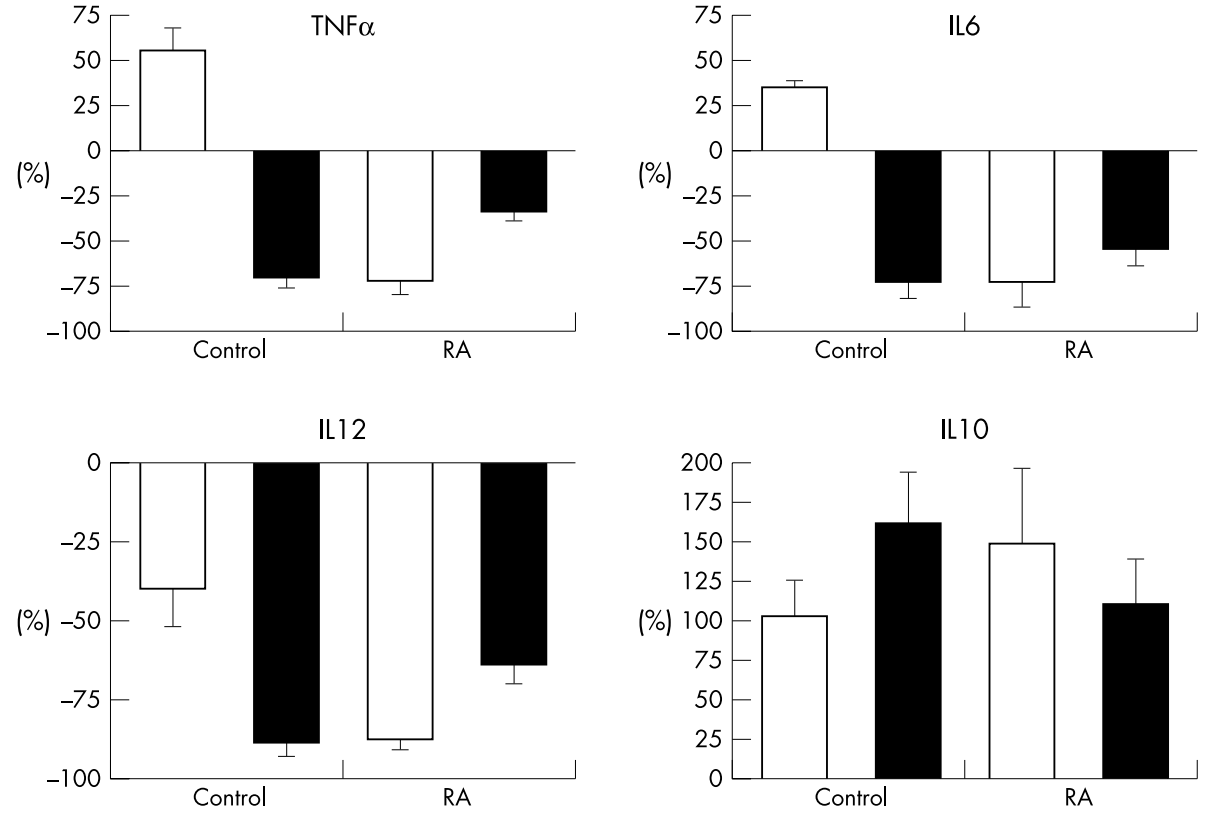

Figure 2 Effect of FcyR triggering on cytokine production by DC from healthy controls and patients with RA after co-culture with IL4 or IL13. The production of TNF $\alpha$, IL6, IL10, and IL12 by DC co-cultured with IL4 or IL13 from healthy controls and patients with RA was measured. The graphs display the percentage of cytokine production upon combined stimulation with LPS and HAGGs compared with that after stimulation with LPS alone.

of the University Medical Centre Nijmegen approved the study protocol.

\section{Generation of monocyte derived DC}

Monocyte derived DC cultures were obtained using essentially the same protocol as described previously. ${ }^{6}$ Briefly, a peripheral blood mononuclear cell fraction was obtained by density gradient centrifugation from full blood. Thereafter, the cells were allowed to adhere for 1 hour at $37^{\circ} \mathrm{C}$ in RPMI1640 , enriched with $2 \%$ heat inactivated human serum. Adherent monocytes were cultured in RPMI-1640, supplemented with $10 \%$ heat inactivated fetal calf serum and antibiotic-antimycotic agent (Life Technologies) in the presence of either IL4 $(500 \mathrm{U} / \mathrm{ml}$; Schering-Plough, Amstelveen, The Netherlands) or IL13 (R\&D systems Inc, USA) alone or in combination and granulocyte monocytecolony stimulating factor ( $800 \mathrm{U} / \mathrm{ml}$; Schering-Plough) for 6 days. To generate fully mature DC (mDC), immature DC (iDC) were transferred to new six well culture plates and cultured for 2 more days in the presence of complete culture medium supplemented with $2 \mu \mathrm{g} / \mathrm{ml}$ lipopolysaccharide (LPS; E coli, Sigma Chemicals, St Louis, MO).

\section{Phenotypic characterisation of $\mathrm{iDC}$ and $\mathrm{mDC}$}

The expression of cell surface markers characterising both iDC and mDC characteristics was checked by fluorescence activated cell sorter (FACS) techniques as described previously. ${ }^{5}$ The following monoclonal antibodies were used as the first layer: CD14, CD16, CD32, CD64 (all DAKO, Glostrup, Denmark), CD80 (Becton Dickinson), CD83 (Beckman Coulter, Mijdrecht, The Netherlands), CD86 (Pharmingen, San Diego, CA, USA), major histocompatibility complex (MHC)-I (clone W6/32), MHC-II DQ (clone SPV-L3), and MHC-II DP/DR (clone Q1513). Cells were gated according to their forward and side scattering patterns. During all FACS procedures, mouse IgG2b was used as an isotype control and the same instrumental settings were used.

\section{Fc $\gamma R$ dependent and independent stimulation of DC} during maturation

To study the effect of Fc $\gamma \mathrm{R}$ mediated triggering, DC stimulated with LPS and heat aggregated gammaglobulins (HAGGs; final concentration $100 \mu \mathrm{g} / \mathrm{ml}$ ) were compared with DC stimulated with LPS alone. To compare IL4 and IL13, DC were costimulated with one of these cytokines. HAGGs were obtained as previously described. ${ }^{16}$ Supernatants were then collected after 48 hours of incubation.

\section{Cytokine and chemokine measurement}

The secretion of the inflammatory mediators ILl, IL6, TNF $\alpha$, IL10, and IL12 by iDC, MDC, and iDC stimulated with HAGGs during maturation was measured using Luminex technology as described in detail previously. ${ }^{25}$

Chemokine expression was studied using real time polymerase chain reaction (PCR) techniques using essentially the same protocol as recently described. ${ }^{6}$ Briefly, the sequence of primers and probes for the chemokines CCL17, CCL18, CCL19, and CCL3 was used as described previously. ${ }^{6}$ The probes specific for the housekeeping genes glyceraldehyde-3phosphate dehydrogenase and porphobilinogen deaminase (PBGD) were labelled with a VIC fluorescent group at the 5' end.

PCR reactions were performed in accordance with the Taqman assay instructions, using an end concentration of $175 \mathrm{nmol} / \mathrm{l}$ probe and $600 \mathrm{nmol} / \mathrm{l}$ primers. ${ }^{26}{ }^{27}$ The amplifications were performed on a ABI/PRISM 7700 sequence detector system (PE-Applied Biosystems).

\section{Fc $\gamma R$ mediates antigen uptake capacity by DC}

To obtain data about the functionality and level of Fc $\gamma$ RII subtypes on IL13 and IL4 DC, we studied the uptake of antigens by these cells, as described previously. ${ }^{28}$ Therefore, human gammaglobulins ( Sigma-Aldrich, St Louis, MO, USA) at a concentration of $10 \mathrm{mg} / \mathrm{ml}$ were labelled with fluorescein isothiocyanate (FITC) using the FluoReporter FITC protein 


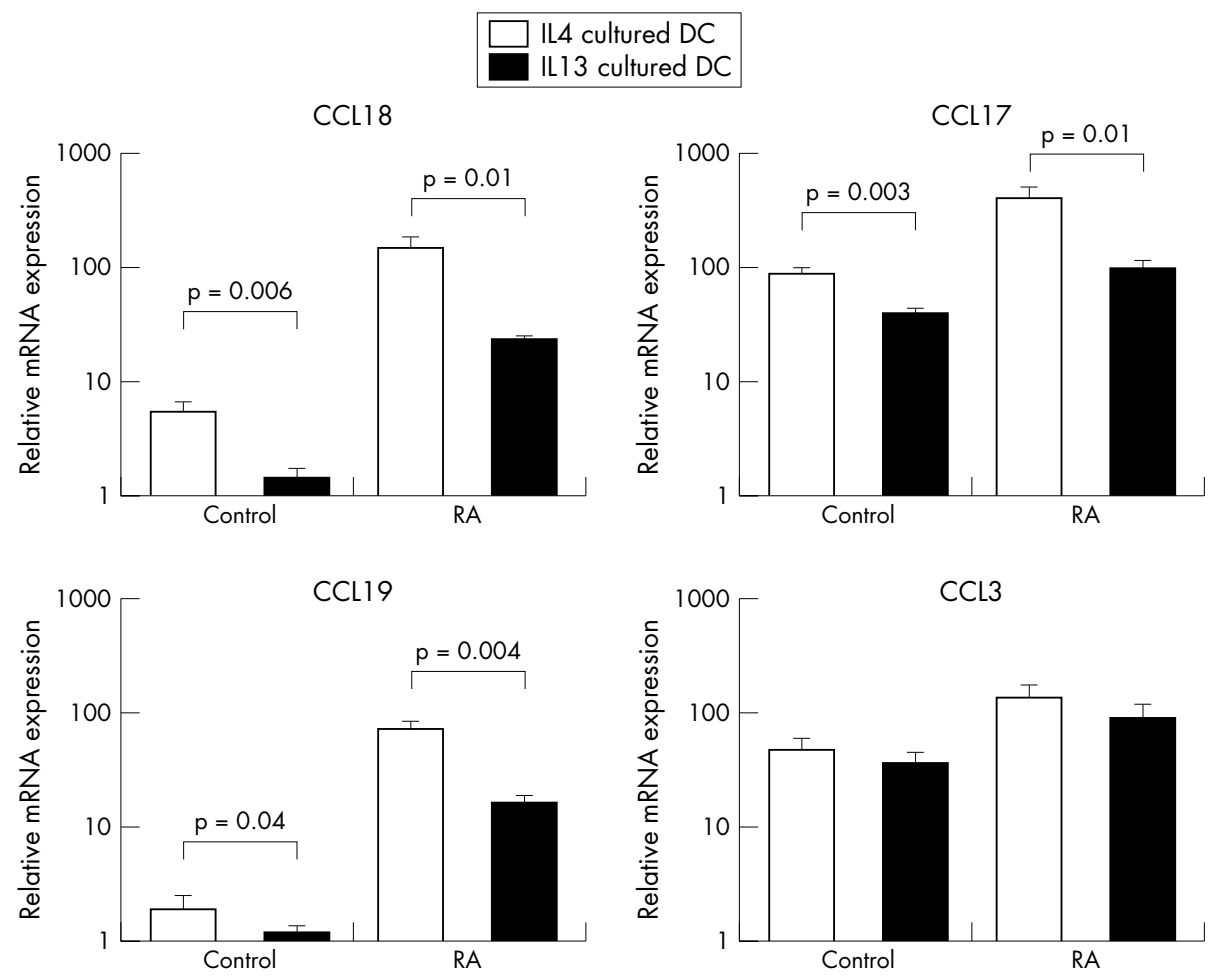

Figure 3 Expression of chemokines CCL18, CCL17, CCL19, and CCL3 by DC co-cultured with IL4 or IL13. mRNA expression of CCL18, CCL17, CCL19, and CCL3 by DC from healthy controls $(n=16)$ and patients with RA $(n=15)$ was measured by real time quantitative PCR techniques. The chemokine expression level by DC co-cultured with IL4 (500 U/ml) was compared with that co-cultured with ILI3 (5 ng/ml).

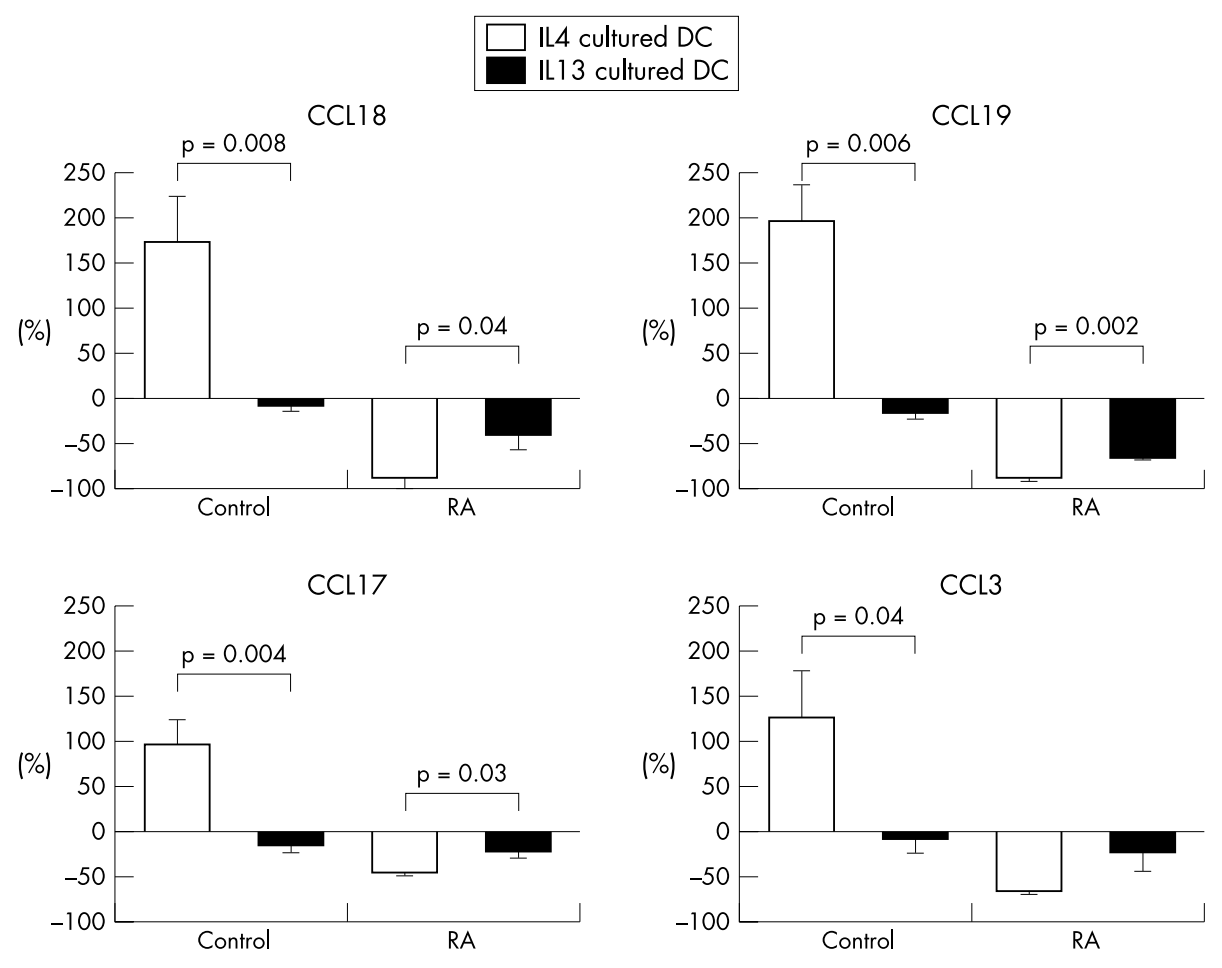

Figure 4 Effect of $F c \gamma R$ triggering on the mRNA expression of chemokines by DC from healthy controls and patients with RA after co-culture with IL4 or IL13. The mRNA expression of CCL18, CCL19, CCL17, and CCL3 by DC co-cultured with IL4 or IL13 from healthy controls and patients with RA was studied. The graphs display the percentage of chemokine expression upon combined stimulation with LPS and HAGGs compared with that after stimulation with LPS alone. 
labelling kit (Molecular Probes, Eugene, OR, USA) and thereafter heated to $63^{\circ} \mathrm{C}$ for 30 minutes. iDC were resuspended in phosphate buffered saline containing $0.1 \%$ bovine serum albumin at a concentration of $4 \times 10^{6}$ cells $/ \mathrm{ml}$. DC from six patients and six healthy subjects were used in six different experiments. Every experiment was performed using simultaneous culture of DC from healthy donors and patients with RA.

\section{RESULTS}

DC phenotype is not altered by stimulation with IL 13 iDC expressed intermediate levels of CD14, costimulatory molecules (CD80 and CD86), and MHC molecules and lacked CD83, the mDC marker (table 1). Upon triggering with LPS, the DC mature which coincides with a decreased expression of CD14, up regulation of CD80, CD86, and MHC and clear expression of CD83. No differences were seen between DC from the 16 healthy controls and the 15 patients with RA.

To study the effect of IL13, we next investigated the phenotype of DC cultured in the presence of IL13. With this aim, we added different concentrations of $\operatorname{IL13}(1,5$, and $20 \mathrm{ng} / \mathrm{ml}$ ) to the DC cultures instead of $500 \mathrm{U} / \mathrm{ml}$ IL4. No phenotypic differences were seen between DC cultured in the presence of IL4 or IL13, either in healthy controls or in those from patients with RA (data not shown).

\section{IL13 mediated up regulation of FcyRII does not occur on DC from patients with RA}

Because we hypothesised that Fc $\gamma$ RII expression by DC might be mediated by IL13, we first studied the effect of IL13 on the expression of Fc $\gamma R$ on DC from healthy donors (CDC, $n=16$ ). Figure 1A shows that the number of Fc $\gamma$ RII expressing (mean (SD) 66 (3) $v 56(5), \mathrm{p}=0.08)$ cells and the mean (SD) fluorescence intensity (MFI) (77 (6) $v 49$ (7), p=0.007) increased upon stimulation with low amounts of IL13 ( $1 \mathrm{ng} /$ $\mathrm{ml})$ compared with that of IL4 $(500 \mathrm{U} / \mathrm{ml})$. The addition of higher concentrations of IL13 $(5 \mathrm{ng} / \mathrm{ml})$ further up regulated Fc $\gamma$ RII positive cells (82 (4), p=0.001) and MFI (123 (5), $\mathrm{p}=0.001$ ) but levelled by $20 \mathrm{ng} / \mathrm{ml}$ of IL13. Therefore, $5 \mathrm{ng} /$ $\mathrm{ml}$ ILl3 was considered to be the optimal concentration for DC in this study.

To investigate whether IL13 would bring about the same effect in RA, DC from patients with RA (RADC, $\mathrm{n}=15$ )) were studied. In corroboration with previous findings from our group, RADC co-cultured with IL4 displayed a higher expression of Fc $\gamma$ RII than CDC (fig 1B). ${ }^{5}$ In contrast, stimulation with IL13 of DC from patients with RA did not significantly alter the number of Fc $\gamma$ RII expressing cells (66
(7) $v 72(3), \mathrm{p}=0.10)$ or the MFI (91 (15) $v 77(12), \mathrm{p}=0.09)$ (fig 1B).

Of note, the percentage IL4 DC that expressed Fc $\gamma$ RI and FC $\gamma$ RIII was similar to that of IL13 DC both from healthy controls (Fc $\gamma$ RI: 15 (14) v 23 (16), Fc $\gamma$ RIII: 15 (13) v 22 (19)) and patients with RA (Fc $\gamma$ RI: 15 (6) $v 16$ (9), Fc $\gamma$ RIII: 15 (8) $v$ $20(10)$ ). The same trend was seen for the MFI (data not shown).

\section{Altered regulation of $\mathrm{Fc} \gamma \mathrm{RII}$ has functional consequences for the production of cytokines upon $F c \gamma R$ mediated triggering}

We hypothesised that IL13 mediates selective up regulation of FC $\gamma$ RIIb on CDC but not on RADC and envisaged that this would affect the secretion of cytokines upon Fc $\gamma R$ mediated triggering.

Figure 2 shows that Fc $\gamma \mathrm{R}$ mediated triggering of IL4 CDC significantly increased secretion of $\mathrm{TNF} \alpha(56 \%)$ and IL6 (34\%), IL10 (100\%), whereas IL12 secretion was inhibited (40\%), which is in line with previously published reports. ${ }^{16}$ In contrast, IC mediated triggering of IL13 DC led to a clearly decreased production of TNF $\alpha(68 \%, \mathrm{p}<0.001)$ and IL6 $(73 \%$, $\mathrm{p}<0.001)$, a further decrease of IL12 $(89 \%, \mathrm{p}=0.02)$ and further increased production of IL10 (162\%, p<0.01). These results demonstrate that IL13 mediated up regulation of FC $\gamma$ RII on CDC clearly results in inhibitory DC phenotype upon Fc $\gamma$ R mediated triggering in comparison with IL4 DC.

We next analysed whether the altered IL13 mediated regulation of FC $\gamma$ RII expression as seen in DC from patients with RA affects the cytokine production upon Fc $\gamma$ R mediated stimulation. IL4 DC from patients with RA decreased the secretion of TNF $\alpha(p=0.001)$, IL6 $(p=0.002)$, and IL12 $(\mathrm{p}=0.001)$ upon stimulation with IC whereas the production of ILl0 ( $p=0.002)$ increased (fig 2), indicating that RADC already display an inhibitory subtype, which is in line with previous research from our group. ${ }^{16}$ Intriguingly, IL13 RADC failed to inhibit the production of TNF $\alpha$, IL6, and IL12 production as potently as IL4. Similarly, the up regulation of IL10 production upon IC mediated triggering was less with IL13 DC than with IL4 DC (fig 2). These results thus parallel our findings seen with FACS analysis and suggest that the IL13 mediated regulation of FC $\gamma$ RIIb on DC is severely altered in RA. The administration of non-heated IgG did not have any effect on DC for cytokine production. Of note, we tested whether a potentially different expression of the IL13 receptor might explain the altered response to IL13 between DCs from healthy controls and patients with RA. However,
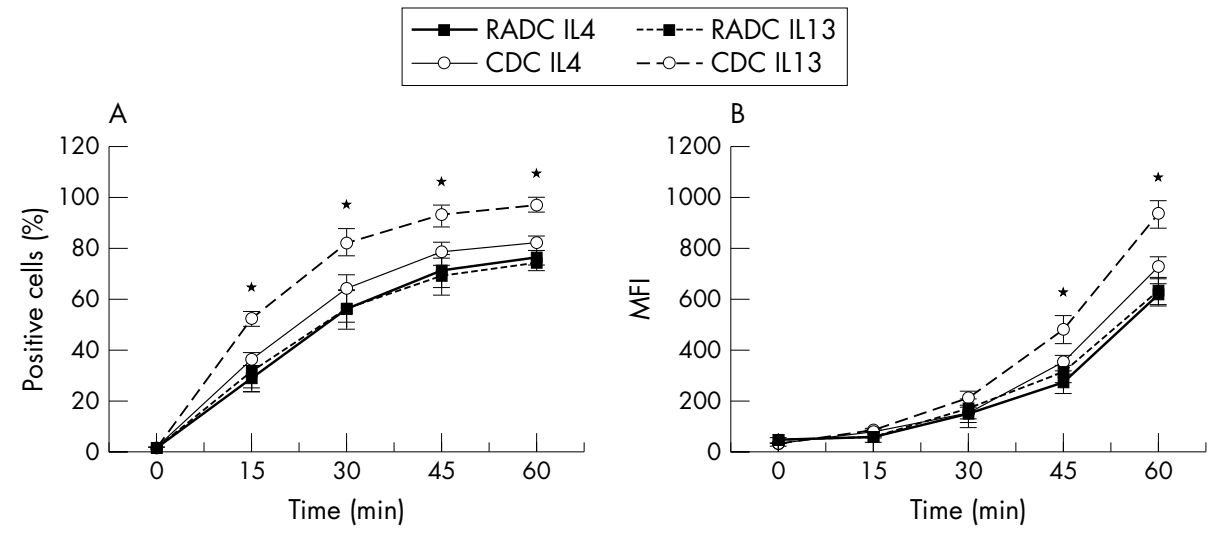

Figure 5 IL13 mediated regulation of FcyR dependent uptake of fluorescent HAGGs. The percentage of fluorescent cells (A) and mean fluorescence intensity (B) as a marker for uptake of fluorescent HAGGs over a period of time is shown ( $x$ axis). DC from patients with RA ( $n=6$ ) co-cultured with IL13 or IL4 are compared with CDC ( $=6)$ co-cultured with IL13 and IL4 respectively. ${ }^{*} \mathrm{p}<0.05$. 
the expression of IL13 receptor was similar between the two groups (data not shown).

\section{Fc $\gamma R$ mediated inhibition of chemokine expression by CDC is absent in RADC}

DC are involved in the attraction of T cells, which is mainly orchestrated by the excretion of chemokines. We investigated the effects of IL13 on expression of the chemokines CCL17, CCL18, CCL19, and CCL3 both by FC $\gamma \mathrm{R}$ independent and dependent pathways.

IL13 CDC expressed significantly less of the chemokines CCL17 $(p=0.003$ and $p=0.01), \operatorname{CCL} 18 \quad(p=0.006$ and $\mathrm{p}=0.01)$, and CCL19 $(\mathrm{p}=0.04$ and $\mathrm{p}=0.004)$ than IL4 DC in healthy donors and patients with RA, respectively (fig 3). The same trend was seen for CCL3.

IC mediated triggering of IL13 of CDC resulted in a significantly decreased expression of CCL17 $(p=0.004)$, CCL18 $(p=0.008)$, CCL19 $(p=0.006)$, and CCL3 $(p=0.04)$ in comparison with that of IL4 CDC, suggesting that the antiinflammatory effect of IL13 is, at least partly, mediated by Fc $\gamma R$ modulation (fig 4). In contrast with CDC, the expression of CCL17, CCL18, CCL19, and CCL3 was less efficiently inhibited by IL13 DC from patients with RA after stimulation with IC. This further substantiates the finding that DC from healthy controls respond differently to IL13 than DC from patients with RA, which might have profound biological consequences for the response on IC.

\section{IL 13 increases IC uptake capacity of CDC but not of RADC}

Fc $\gamma$ RII is important in the uptake and processing of antigenimmune complexes. Therefore, we studied whether different expression of Fc $\gamma$ RII on stimulation with IL13 between CDC and RADC has consequences for the antigen uptake capacity by performing six consecutive cultures, each taking one patient with RA and one healthy control simultaneously. Figure 5 shows that stimulation of CDC with IL13 increased the uptake of immunoglobulins compared with IL4 DC both for the number of positive cells $(p=0.03)$ and mean fluorescence intensity $(p=0.02)$. In sharp contrast with CDC, the antigen uptake capacity by RADC was not increased by IL13 and was similar to that of CDC cultured with IL4. Because Fc $\gamma$ RI and Fc $\gamma$ RIII are also involved in the uptake of IC, we measured the expression of these Fc $\gamma \mathrm{R}$ subtypes as well. Both Fc $\gamma$ RI and Fc $\gamma$ RIII were expressed at similar levels on IL4 and IL13 DC from both patients with RA and healthy controls.

\section{DISCUSSION}

Here we demonstrate that replacement of IL4 by IL13 during culture clearly increases expression of Fc $\gamma$ RII on CDC, whereas this effect is absent on RADC. This phenomenon could not be explained by a potential relative resistance for IL13 of RADC, because IL13 itself strongly inhibits the production of inflammatory mediators equally for RADC and CDC, or by IL13 receptor expression because this was found to be similar for CDC and RADC (data not shown). In addition, we demonstrated that the altered response to IL13 seen by RADC has major consequences for the production of inflammatory mediators upon stimulation of Fc $\gamma$ R dependent pathways. The functionality of this IL13 mediated up regulation of Fc $\gamma$ RII was further substantiated by the finding that IL13 increased the antigen uptake capacity by DC from healthy donors but failed to orchestrate the same effect on DC from patients with RA. Intriguingly, RADC co-cultured with IL4 already displayed a diminished capacity for IC uptake in comparison with those from healthy controls. Because the cell surface expression of Fc $\gamma$ RII was found to be higher on RADC, there might also be a defect in the functionality of the Fc $\gamma$ RII in RA which needs to be examined in further studies.

DC express high levels of $\mathrm{Fc} \gamma \mathrm{R}$ and are at least partly controlled by the triggering of these receptors. The expression of Fc $\gamma \mathrm{R}$ expression is tightly regulated by many pro- and antiinflammatory cytokines, of which IL4 and IFN $\gamma$ have been the most thoroughly investigated. Although, the effects of IL4 on monocytes and macrophages on phenotype and function are largely known, the effect on DC has not been similarly scrutinised. IL4 is not present in large quantities during synovial pathology, which makes an important role less likely. In contrast, IL13, a cytokine generally accepted as having potent anti-inflammatory effects, shares many biological functions with IL4 and is present in large amounts during synovial inflammation. ${ }^{18} 192930$ The presence of IL13 in RA serum and synovial fluid was further substantiated by the finding that the blockade of IL13 in RA serum and synovial fluid, at least partly, diminished the up regulation of Fc $\gamma$ RIIb (manuscript in preparation). To our knowledge, the precise effects of IL13 on FC $\gamma$ R expression have not yet been determined. Here we present new data which suggests that IL13 mediates the up regulation of Fc $\gamma$ RIIb more potently than IL4, which is translated into a FC $\gamma$ R mediated inhibitory DC phenotype in healthy subjects. In addition, we provide firm evidence that in RA such Fc $\gamma$ RII regulatory mechanism seems to be unresponsive to IL13, which might potentially result in a failure to mount an adequate inhibitory response to IC.

Every signal that ignites the immune response has to be terminated to prevent the establishment of chronic inflammation. Envisaged in the light of DC function, the main task of which is to prime $\mathrm{T}$ cells and thus control the balance between immunity or tolerance, it is tempting to speculate that the balance between activating and inhibiting Fc $\gamma R$ should act as a counteractive mechanism to dampen the proinflammatory response after elimination of the provocative factor. Such a counteractive mechanism is perhaps set in motion by the production of IL13 during the early phases of inflammation. Later on in the immune response, when IL13 production subsides, the balance of the expression of Fc $\gamma \mathrm{R}$ is altered towards the inhibitory subtype. Subsequent triggering by IC, produced in large quantities during later stages of an immune response, activate inhibitory pathways through Fc $\gamma R$ mediated mechanisms aimed at dampening the proinflammatory response and restoring an immunological steady state. In RA, however, this counteractive mechanism fails for yet unidentified reasons, potentially leading to a vicious circle of uncontrolled proinflammatory responses, which ultimately result in irreversible joint destruction as seen in RA.

The critical role for $F c \gamma R$ in the orchestration and polarisation of immune responses has recently been studied by Anderson et al, who demonstrated that macrophages can direct the production of antigen-specific $\mathrm{T}$ cells, which preferentially produce Th2 cytokines, exclusively when triggered with antigen directed against Fc $\gamma \mathrm{R} .{ }^{31}{ }^{32}$ In addition, the development of immunity or tolerance against tumour antigens was largely dependent on the balance between activating or inhibitory Fc $\gamma R .^{33}$ Further evidence for a role of Fc $\gamma R$ in the modulation of autoimmunity is provided by the fact that intravenous immunoglobulins are beneficial in several inflammatory conditions. ${ }^{34-36}$ The fact that intravenous immunoglobulins are ineffective in the treatment of RA underlines our finding that such counteractive mechanism, mediated by $\mathrm{F} c \gamma \mathrm{R}$, is defective in this condition. ${ }^{37}$

In conclusion, we provide evidence for an aberrant expression and regulation of the inhibitory Fc $\gamma$ RIIb by IL13 on DC from patients with RA, which has profound functional consequences. Because inhibitory Fc $\gamma \mathrm{R}$ are pivotal for the regulation of immune responses a potentially defective 
Fc $\gamma$ RII regulation might explain why RA is a chronic, Thl driven disease. Because DC treatment in autoimmune diseases holds great promise, further research into the responsible pathways involved in Fc $\gamma \mathrm{R}$ mediated DC function might lead to new therapeutic targets.

\section{Authors' affiliations \\ T R D J Radstake, K C A M Nabbe, M H Wenink, M F Roelofs,} A Oosterlaar, A W T van Lieshout, P Barrera, P L E M van Lent, W B van den Berg, Department of Rheumatology and Laboratory of Experimental Rheumatology and Advanced Therapeutics, University Medical Centre Nijmegen, Nijmegen, The Netherlands

Funding: This project has been supported by the Foundation "de Drie Lichten" in the Netherlands.

\section{REFERENCES}

1 Tak PP, Bresnihan B. The pathogenesis and prevention of joint damage in rheumatoid arthritis: advances from synovial biopsy and tissue analysis. Arthritis Rheum 2000;43:2619-33.

2 Steinman RM, Nussenzweig MC. Inaugural article: avoiding horror autotoxicus: The importance of dendritic cells in peripheral T cell tolerance. Proc Natl Acad Sci USA 2002;99:351-8.

3 Page G, Lebecque S, Miossec P. Anatomic localization of immature and mature dendritic cells in an ectopic lymphoid organ: correlation with selective chemokine expression in rheumatoid synovium. J Immunol 2002; 168:5333-41.

4 Thomas R, Davis LS, Lipsky PE. Rheumatoid synovium is enriched in mature antigen-presenting dendritic cells. J Immunol 1994;152:2613-23.

5 Radstake TR, Blom A, Sloetjes A, van Gorselen EO, Pesman GJ, Engelen L, et al. Elevated FcgammaRIl expression and aberrant tumour necrosis factor alpha production by mature dendritic cells from patients with active rheumatoid arthritis. Ann Rheum Dis 2004;63:1556-63.

6 Radstake TR, van der Voort R, ten Brummelhuis M, De Waal MM, Schreurs W, Looman $M$, et al. Increased expression of CCL18, CCL19, and CCL17 by dendritic cells from patients with rheumatoid arthritis and regulation by $\mathrm{Fc}$ gamma receptors. Ann Rheum Dis 2005:64:359-67.

7 Morita Y, Yang J, Gupta R, Shimizu K, Shelden EA, Endres J, et al. Dendritic cells genetically engineered to express IL- 4 inhibit murine collagen-induced arthritis. J Clin Invest 2001;107:1275-84.

8 Leung BP, Conacher M, Hunter D, Mclnnes IB, Liew FY, Brewer JM. A novel dendritic cell-induced model of erosive inflammatory arthritis: distinct roles for dendritic cells in T cell activation and induction of local inflammation. $J$ Immunol 2002; 169:7071-7.

9 Sutton B, Corper A, Bonagura V, Taussig M. The structure and origin of rheumatoid factors. Immunol Today 2000;21:177-83.

10 Dijstelbloem HM, van De Winkel JG, Kallenberg CG. Inflammation in autoimmunity: receptors for lgG revisited. Trends Immunol 2001 ;22:510-16.

11 Salmon JE, Pricop L. Human receptors for immunoglobulin G: key elements in the pathogenesis of rheumatic disease. Arthritis Rheum 2001:44:739-50.

12 Malbec O, Fridman WH, Daeron M. Negative regulation of hematopoietic cell activation and proliferation by Fc gamma RIIB. Curr Top Microbiol Immunol 1999;244:13-27.

13 Qin D, Wu J, Vora KA, Ravetch JV, Szakal AK, Manser T, et al. Fc gamma receptor IIB on follicular dendritic cells regulates the $B$ cell recall response. $\mathrm{J}$ Immunol 2000;164:6268-75

14 Yuasa T, Kubo S, Yoshino T, Ujike A, Matsumura K, Ono M, et al. Deletion of fcgamma receptor IIB renders $\mathrm{H}-2$ (b) mice susceptible to collagen-induced arthritis. J Exp Med 1999;189:187-94.

15 Pricop L, Redecha P, Teillaud JL, Frey J, Fridman WH, Sautes-Fridman C, et al. Differential modulation of stimulatory and inhibitory Fc gamma receptors on human monocytes by Th1 and Th2 cytokines. J Immunol 2001; 166:531-7.

16 Radstake TR, van Lent PL, Pesman GJ, Blom AB, Sweep FG, Ronnelid J, et al. High production of proinflammatory and Th1 cytokines by dendritic cells from patients with rheumatoid arthritis, and down regulation upon Fc\{gamma\}R triggering. Ann Rheum Dis 2004;63:696-702.
17 Miossec P, Naviliat M, Dupuy DA, Sany J, Banchereau J. Low levels of interleukin-4 and high levels of transforming growth factor beta in rheumatoid synovitis. Arthritis Rheum 1990;33:1180-7.

18 Isomaki P, Luukkainen R, Toivanen P, Punnonen J. The presence of interleukin13 in rheumatoid synovium and its antiinflammatory effects on synovial fluid macrophages from patients with rheumatoid arthritis. Arthritis Rheum 1996;39:1693-702.

19 Tokayer A, Carsons SE, Chokshi B, Santiago-Schwarz F. High levels of interleukin 13 in rheumatoid arthritis sera are modulated by fumor necrosis factor antagonist therapy: association with dendritic cell growth activity. J Rheumatol 2002;29:454-61.

20 van Lent $P L$, van Vuuren $A J$, Blom $A B$, Holthuysen $A E$, van De Putte $L B$, van $D e$ Winkel JG, et al. Role of $F c$ receptor gamma chain in inflammation and cartilage damage during experimental antigen-induced arthritis. Arthritis Rheum 2000;43:740-52.

21 Diaz de Stahl T, Andren M, Martinsson P, Verbeek JS, Kleinau S. Expression of FcgammaRIII is required for development of collagen-induced arthritis. Eur J Immunol 2002;32:2915-22.

22 Nabbe KC, van Lent PL, Holthuysen AE, Kolls JK, Verbeek S, van Den Berg WB. FcgammaRI up-regulation induced by local adenoviral-mediated interferon-gamma production aggravates chondrocyte death during immune complex-mediated arthritis. Am J Pathol 2003;163:743-52.

23 Nandakumar KS, Andren M, Martinsson P, Bajtner E, Hellstrom S, Holmdahl $R$, et al. Induction of arthritis by single monoclonal lg $G$ anti-collagen type II antibodies and enhancement of arthritis in mice lacking inhibitory FcgammaRIIB. Eur J Immunol 2003;33:2269-77.

24 Arnett FC, Edworthy SM, Bloch DA, McShane DJ, Fries JF, Cooper NS, et al. The American Rheumatism Association 1987 revised criteria for the classification of rheumatoid arthritis. Arthritis Rheum 1988:31:315-24.

25 de Jager W, te Velthuis H, Prakken BJ, Kuis W, Rijkers GT. Simultaneous detection of 15 human cytokines in a single sample of stimulated peripheral blood mononuclear cells. Clin Diagn Lab Immunol 2003;10:133-9.

26 Gibson UE, Heid CA, Williams PM. A novel method for real time quantitative RT-PCR. Genome Res 1996;6:995-1001.

27 Heid CA, Stevens J, Livak KJ, Williams PM. Real time quantitative PCR. Genome Res 1996:6:986-94.

28 van Striip JA, van Kessel KP, van der Tol ME, Verhoef J. Complementmediated phagocytosis of herpes simplex virus by granulocytes. Binding or ingestion. J Clin Invest 1989;84:107-12.

29 de Waal MR, Figdor CG, Huijbens R, Mohan-Peterson S, Bennett B, Culpepper J, et al. Effects of IL-13 on phenotype, cytokine production, and cytotoxic function of human monocytes. Comparison with IL-4 and modulation by IFN-gamma or IL-10. J Immunol 1993;151:6370-81.

30 Jovanovic D, Pelletier JP, Alaaeddine N, Mineau F, Geng C, Ranger P, et al. Effect of IL-13 on cytokines, cytokine receptors and inhibitors on human osteoarthritis synovium and synovial fibroblasts. Osteoarthritis Cartilage 1998;6:40-9.

31 Anderson CF, Mosser DM. Cutting edge: biasing immune responses by directing antigen to macrophage fcgamma receptors. J Immunol 2002; 168:3697-701

32 Anderson CF, Mosser DM. A novel phenotype for an activated macrophage: the type 2 activated macrophage. J Leukoc Biol 2002;72:101-6.

33 Kalergis AM, Ravetch JV. Inducing tumor immunity through the selective engagement of activating Fcgamma receptors on dendritic cells. J Exp Med 2002; 195: 1653-9.

34 Cherin P, Pelletier S, Teixeira A, Laforet P, Genereau T, Simon A, et al. Results and long-term followup of intravenous immunoglobulin infusions in chronic refractory polymyositis: an open study with thirty-five adult patients. Arthritis Rheum 2002;46:467-74.

35 van der Meche FG, Schmitz PI. A randomized trial comparing intravenous immune globulin and plasma exchange in Guillain-Barre syndrome. Dutch Guillain-Barre Study Group. N Engl J Med 1992;326: $1123-9$.

36 Sorensen PS, Wanscher B, Jensen CV, Schreiber K, Blinkenberg M, Ravnborg $M$, et al. Intravenous immunoglobulin $G$ reduces $M R I$ activity in relapsing multiple sclerosis. Neurology 1998;50:1273-81.

37 Kanik KS, Yarboro CH, Naparstek Y, Plotz PH, Wilder RL. Failure of low-dose intravenous immunoglobulin therapy to suppress disease activity in patients with treatment-refractory rheumatoid arthritis. Arthritis Rheum 1996;39:1027-9 